\title{
The Year Ahead
}

It is a great honor to serve the members of the Materials Research Society in 1994 as its 19th president. As my involvement with MRS has grown over the past decade, I have often looked for new ways to contribute and new opportunities for growth and improvement in the services that the Society provides. I have been deeply impressed with the commitment of the volunteers who make MRS the outstanding society that it is, the dedication of the staff in Pittsburgh, and the breadth and quality of our technical meetings and publication activities. We have much to be proud of, and I am delighted to be part of this outstanding organization.

Beyond fulfilling the normal responsibilities of office, I have the following goals as 1994 MRS president:

- Lay the Groundwork for Electronic Delivery of Member Services. During the past year the Society has established an electronic mail system for its headquarters staff, enabling rapid communication between themselves and officers and key volunteers. This has already greatly improved our business practices, and has made for more efficient use of everyone's time. For 1994 it will be our task to prepare headquarters to deal with the volume of e-mail anticipated when we open the door for general communication with Society members. Once those systems are in hand, we expect to move toward accepting manuscripts for the MRS Bulletin and Joumal of Materials Research via electronic means, maintaining a variety of online databases related to such things as technical information about materials, calendars of upcoming meetings, and job-search listings, and providing online meeting registration. Electronic publishing will no doubt also be on our agenda. Implementing these and other services must be effected within guidelines dictated by financial prudence, but

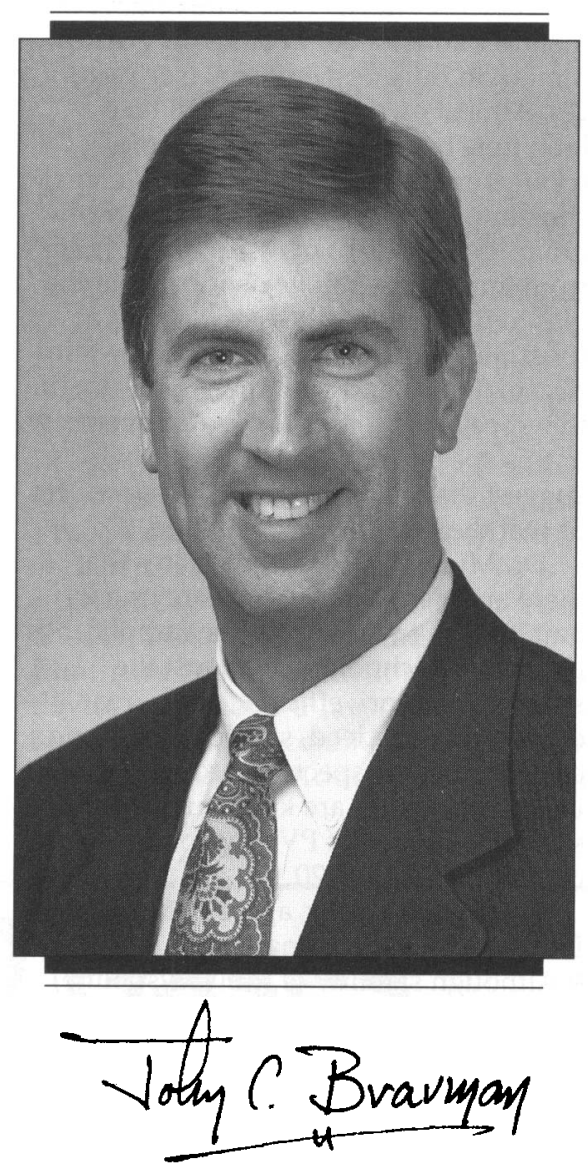

I am convinced that we ought to and must move in this direction.

Continue Service to the Materials Community Through Active Participation in Relevant Washington, DC Activities. Over the past few years the Society has played a significant role in the capitol through its support and sponsorship of technical and policy meetings and forums, through direct meetings with key members of Congress and the administration, and through cooperation with other materials-related societies. As broad questions of science policy are now being debated at the highest levels of government, it is essential that the materials community be well represented. While we have not and will not lobby for specific legislation, we will carry a brief for the importance of materials research to whomever is appropriate. Our Washington Office of Public Affairs has already provided important leadership in this area, as have a number of Society volunteers.

Maintain the Excellence and Diversity of Our Technical Meetings. No matter what else we may do, our Spring and Fall Meetings remain the heart and soul of MRS. As any regular attendee knows, these meetings have grown impressively in size and scope over the past decade. It's clear that the limits of our present facilities have been reached, and that decisions need to be made about how the meetings can grow further, whether or not they should, and how to fund new programs. We are considering additional meeting sites, alternative and/or additional meeting dates, and new meeting formats. And, of course, whatever we do must not be at the expense of the diversity and flexibility which have become hallmarks of MRS meetings.

Back in the fall of 1982, when I presented my first paper at an MRS meeting, I certainly had no idea that just 12 years later it would be my privilege to serve the Society as its president. As I begin my term of office and look back at where we as a Society have been, and then speculate as to where we might travel in the years ahead, I am struck by the breadth of opportunities for the materials research community, even in these difficult and uncertain times. I hope that, together, we can find many ways to make this a fruitful and pleasurable journey.

JOHN C. BRAVMAN 